\title{
Integrating TOPSIS and AHP into GORE Decision Support System
}

\author{
Vinay S \\ NMAMIT, Nitte, India
}

\author{
Shridhar Aithal \\ TAPMI, Manipal, India
}

\author{
Sudhakara G \\ MIT, Manipal, India
}

\begin{abstract}
Decision making in Software Engineering plays an important role at different stages of Software development life cycle. In this paper we consider the case study of selecting one among the three Content Management Systems (CMS) for a university website. We use our Goal-Oriented Requirements Engineering (GORE) method to identify the soft goals which play a vital role in deciding which CMS is chosen. Analytic Hierarchy Process (AHP) is then used to prioritize the soft goals. The output of AHP is used as input to Technique for Order of Preference by Similarity to Ideal Solution (TOPSIS) which produces a metric which decides the best alternative among the candidates.
\end{abstract}

\section{General Terms}

Requirements Engineering, Decision Support System

\section{Keywords}

GoalOriented Requirements Engineering, Analytic Hierarchy Process, Technique for Order of Preference by Similarity to Ideal Solution, Soft goals

\section{INTRODUCTION}

It is well acknowledged in Software Engineering that while functional requirements are important, eliciting and capturing the non-functional requirements (NFR) during the requirements engineering phase becomes even more important [1]. Goal-oriented requirements engineering (GORE) approaches make a good attempt to address the essential quality characteristics which are commonly known as nonfunctional requirements $[2,3]$. NFRs play a major role in coming up with alternative system configurations for a given functionality.

Gunther Rahe in his paper [6] highlights the importance of Decision Support system (DSS) in Software Engineering. Decisions are the driving engines for all stages of software development and evolution. Decisions can be related to methods, tools, and techniques. Decisions are aimed at answering the questions 'How'? 'How good'? 'When'? 'Why'? and 'Where'? The objective is to have a sound methodology which provides rationale for the decision arrived at. The importance of decision making techniques is also addressed in [7, 8 and 9]. The importance of stakeholders in decision making is done in [10]. Architecture decision making is closely linked to requirements engineering and the aspects related to this are addressed in [11] and [12]. A survey of various requirements prioritization techniques is undertaken in [13]. Decision-Making in Software Engineering is extremely challenging because of a dynamically changing environment, conflicting stakeholder objectives, constraints, coupled with a high degree of uncertainty and vagueness of the available information.

The Analytic Hierarchy Process (AHP) is based on the experience gained by its developer, T.L. Saaty [12], while directing research projects in the US Arms Control and Disarmament Agency. AHP is a well established process used as an aid to decision making when confronted with multiple stakeholders, competing and conflicting objectives, constraints and environments. AHP has been widely used across multiple domains in business, government, social studies, R\&D, defence and other domains involving decisions in which choice, prioritization or forecasting is essential [12].

Technique for Order of Preference by Similarity to Ideal Solution (TOPSIS) method is presented in Chen and Hwang [21], with reference to Hwang and Yoon [22]. The basic principle is that the chosen alternative should have the shortest distance from the ideal solution and the farthest distance from the negative-ideal solution. Combining our GORE method with AHP and TOPSIS in decision making provides adequate rationale for the decision arrived at.

In this paper we consider the case study of selecting one among the three Content Management Systems (CMS) for a university website. We use our Goal-Oriented Requirements Engineering (GORE) method to identify the soft goals which play a vital role in deciding which CMS is chosen. Analytic Hierarchy Process (AHP) is then used to prioritize the soft goals. The output of AHP is used as input to Technique for Order of Preference by Similarity to Ideal Solution (TOPSIS) which produces a metric which decides the best alternative among the candidates. In Section 2 and 3, we discuss our proposed approach and highlight how our GORE approach is used for identifying soft goals (non-functional requirements), their contribution links to each of the alternative. Section 4 discusses how AHP is used to prioritize the soft goals. Combining the output of GORE with TOPSIS and AHP is discussed in Section 5. The effectiveness of the proposed method is discussed in Section 6.

\section{PROPOSED APPROACH}

The major steps involved in our proposed approach are shown in Table 1: 
Table 1. Steps involved in our approach.

\begin{tabular}{|c|c|c|c|c|}
\hline Step & Description & $\begin{array}{r}\text { Input } \\
\end{array}$ & $\begin{array}{r}\text { Method } \\
\end{array}$ & Output \\
\hline 1 & $\begin{array}{ll}\text { Identify } & \text { the } \\
\text { alternatives }\end{array}$ & $\begin{array}{l}\text { The application to be developed, } \\
\text { domain knowledge of the application, } \\
\text { existing system documentation if any, } \\
\text { interview transcripts. }\end{array}$ & $\begin{array}{l}\text { Apply our GORE method to identify } \\
\text { alternatives to achieve a hard goal or } \\
\text { functional requirement. }\end{array}$ & $\begin{array}{lr}\text { A goal } & \text { graph } \\
\text { comprising } & \text { hard } \\
\text { goals along } & \text { with } \\
\text { AND / } & \text { OR } \\
\text { decompositions. } & \end{array}$ \\
\hline 2 & $\begin{array}{l}\text { Identify soft } \\
\text { goals (non- } \\
\text { functional } \\
\text { requirements) }\end{array}$ & $\begin{array}{l}\text { Elicited quality (soft) goals } \\
\text { various strom } \\
\text { application to be developed. }\end{array}$ & $\begin{array}{l}\text { Apply our GORE method to identify soft } \\
\text { goals which affect decision making. Apply } \\
\text { the guidelines for identifying soft goals; } \\
\text { decompose the soft goals wherever } \\
\text { appropriate. }\end{array}$ & $\begin{array}{l}\text { A goal graph } \\
\text { comprising both hard } \\
\text { and soft goals with } \\
\text { AND } / \\
\text { decompositions. }\end{array}$ \\
\hline 3 & $\begin{array}{l}\text { Identify } \\
\text { contribution } \\
\text { links }\end{array}$ & $\begin{array}{l}\text { A goal graph comprising both hard } \\
\text { and soft goals with AND / OR } \\
\text { decompositions; Elicited views of } \\
\text { various stakeholders on goal } \\
\text { dependencies. }\end{array}$ & $\begin{array}{l}\text { Apply our GORE method to identify } \\
\text { contribution links between soft goals and } \\
\text { hard goals ; Contribution links can be }++,+ \text {, } \\
\text { - or -- }\end{array}$ & $\begin{array}{l}\text { A goal graph } \\
\text { comprising both hard } \\
\text { and soft goals with } \\
\text { AND / OR } \\
\text { decompositions and } \\
\text { contribution links. }\end{array}$ \\
\hline 4 & $\begin{array}{l}\text { Calculate } \\
\text { priority of soft } \\
\text { goals }\end{array}$ & $\begin{array}{l}\text { Soft goals with AND decompositions } \\
\text { or multi level hierarchy. }\end{array}$ & $\begin{array}{l}\text { Use AHP to calculate priority of soft goals. If } \\
\text { it is a multi-level hierarchy, we need to } \\
\text { proceed from root to leaf level soft goals in } \\
\text { calculating priorities of soft goals using } \\
\text { AHP. Local weights are calculated among } \\
\text { same level goals using AHP. Global weights } \\
\text { are the product of all local weights } \\
\text { proceeding from leaf to root. }\end{array}$ & $\begin{array}{l}\text { Global weights of all } \\
\text { the leaf level soft } \\
\text { goals. }\end{array}$ \\
\hline 5 & $\begin{array}{l}\text { Evaluation of } \\
\text { each alternative } \\
\text { using TOPSIS }\end{array}$ & $\begin{array}{l}\text { Alternatives; Global weights of all leaf } \\
\text { level soft goals which were computed } \\
\text { using AHP; Contribution links }\end{array}$ & $\begin{array}{l}\text { Convert contribution link to numeric values. } \\
\text { These numeric values will be used in } \\
\text { TOPSIS method. }\end{array}$ & $\begin{array}{l}\text { A number for each of } \\
\text { the alternative. }\end{array}$ \\
\hline 7 & $\begin{array}{l}\text { Ranking } \\
\text { alternatives }\end{array}$ & $\begin{array}{l}\text { Each alternative will have a numeric } \\
\text { value associated with it. }\end{array}$ & $\begin{array}{l}\text { The alternatives are ranked in terms of } \\
\text { increasing order of their values. }\end{array}$ & $\begin{array}{l}\text { One with the highest } \\
\text { value is chosen as the } \\
\text { preferred alternative }\end{array}$ \\
\hline
\end{tabular}

\section{IDENTIFYING SOFT GOALS AND CONTRIBUTION LINKS USING GORE METHODOLOGY}

Some of the prominent GORE methods include: Keep All Objectives Satisfied (KAOS) method [13], Tropos [14], NFR framework $[2,15]$. Our GORE method retains the generic features of other techniques in extracting hard and soft goals, decomposing the goals and refining them. In addition to these, we give more emphasis on identifying the contribution links. Many methods have taken this approach of representation. In our approach we propose the following links: ++, +, -- or -. The symbols and their meanings are shown in first two columns Table 2. The significance of the values mentioned in the third column is discussed in section 5. The method of identifying these contribution links which could be either quantitative or qualitative can be found in our earlier work [16].

In our case study the hard goals are the three CMS which are the candidate choices for designing University website. The first task in our proposed approach is to identify all the soft goals which play a vital role in deciding the best alternative.
Table 2. Meaning of Contribution Links

\begin{tabular}{|c|l|c|}
\hline Symbol & \multicolumn{1}{|c|}{ Meaning } & Value \\
\hline++ & $\begin{array}{l}\text { A hard goal requirement is } \\
\text { fully supported by the soft } \\
\text { goal. }\end{array}$ & 9 \\
\hline+ & $\begin{array}{l}\text { A hard goal requirement is } \\
\text { partially supported by the soft } \\
\text { goal. }\end{array}$ & 7 \\
\hline- & $\begin{array}{l}\text { A hard goal requirement is } \\
\text { supported very minimally by } \\
\text { the soft goal. }\end{array}$ & 3 \\
\hline-- & $\begin{array}{l}\text { A hard goal requirement is not } \\
\text { supported by the soft goal. }\end{array}$ & 1 \\
\hline
\end{tabular}

The soft goals identified for this particular scenario are shown in the first three columns of table 3. Each of the soft goals could be further AND decomposed into sub-goals. For example, Security has 2 sub-goals and each of these sub-goals have been decomposed into 2 sub-goals each. Table 4 contains description about all the identified leaf level soft goals. The details about the CMS and the criteria chosen to evaluate them are found in [23]. 
Table 3. Soft goals and Contribution links for each of the alternative

\begin{tabular}{|c|c|c|c|c|c|}
\hline Goal (L1) & Sub goal (L2) & Sub goal (L3) & $\begin{array}{c}\text { Drupal } \\
\text { 4.6.5 } \\
\end{array}$ & $\begin{array}{c}\text { e Z Publish } \\
\mathbf{3} \\
\end{array}$ & $\begin{array}{c}\text { MD Pro } \\
1.0 .76 \\
\end{array}$ \\
\hline \multirow[t]{4}{*}{ 1.Security } & \multirow[t]{2}{*}{ 1.1 Application Security } & 1.1.1 Human vs PC Verification & -- & -- & ++ \\
\hline & & 1.1.2 Authentication extensibility & ++ & ++ & ++ \\
\hline & \multirow[t]{2}{*}{ 1.2 Data Security } & 1.2.1 Support SSL Protocol & + & ++ & -- \\
\hline & & 1.2.2 SQL Security & ++ & ++ & ++ \\
\hline \multirow[t]{8}{*}{ 2.Management } & \multirow[t]{5}{*}{ 2.1 Style Management } & 2.1.1 Web-based style & ++ & ++ & ++ \\
\hline & & 2.1.2 Multiple templates per site & ++ & ++ & ++ \\
\hline & & 2.1.3 Multiple menu types & + & + & + \\
\hline & & 2.1.4 Dynamic Menus & -- & -- & -- \\
\hline & & 2.1.5 Multilingual contents & ++ & ++ & ++ \\
\hline & \multirow[t]{3}{*}{ 2.2 Web-Statics } & 2.2.1 Visitor tracking & ++ & -- & ++ \\
\hline & & 2.2.2 Contents tracking & ++ & -- & ++ \\
\hline & & 2.2.3 Log-in History & ++ & -- & -- \\
\hline \multirow[t]{6}{*}{ 3. Ease of Use } & 3.1 Drag and Drop & & ++ & -- & -- \\
\hline & 3.2 Preview & & ++ & ++ & ++ \\
\hline & 3.3 Spell Checker & & ++ & -- & -- \\
\hline & 3.4 Undo (upto 10 levels) & & ++ & ++ & -- \\
\hline & 3.5 Image Resizing & & ++ & ++ & -- \\
\hline & 3.6 File type Conversion & & ++ & -- & -- \\
\hline \multirow[t]{2}{*}{ 4. Efficiency } & 4.1 Static Content export & & -- & ++ & -- \\
\hline & 4.2 Page Caching & & ++ & ++ & -- \\
\hline \multirow[t]{5}{*}{ 5. Help and Support } & 5.1 Manuals & & ++ & ++ & ++ \\
\hline & 5.2 Online Help & & ++ & -- & -- \\
\hline & 5.3 Videos and Demos & & + & -- & -- \\
\hline & 5.4 Mailing list & & + & -- & -- \\
\hline & 5.5 Public forum & & + & -- & -- \\
\hline \multirow{6}{*}{$\begin{array}{l}\text { 6. Richness of built- } \\
\text { in tools }\end{array}$} & $6.1 \mathrm{Blog}$ & & ++ & ++ & -- \\
\hline & 6.2 Chat & & -- & -- & -- \\
\hline & 6.3 Forum & & ++ & ++ & -- \\
\hline & 6.4 Image Gallery & & -- & ++ & -- \\
\hline & 6.5 Graph and chart & & -- & -- & -- \\
\hline & 6.6 Search Engine & & ++ & ++ & ++ \\
\hline
\end{tabular}

Table 4. Description of leaf level soft goals

\begin{tabular}{|c|l|l|}
\hline Identifier & Leaf Level Soft Goal & Description \\
\hline 1 & 1.1 .1 Human vs PC Verification & $\begin{array}{l}\text { The ability to determine whether the user is a human or a machine. The } \\
\text { supportability to Captcha challenge-response protocol. }\end{array}$ \\
\hline 2 & 1.1 .2 Authentication extensibility & $\begin{array}{l}\text { The ability to integrate additional authentication mechanisms beyond the } \\
\text { proprietary authentication protocols. }\end{array}$ \\
\hline 3 & 1.2 .1 Support SSL Protocol & $\begin{array}{l}\text { The ability of the system to work with a secure socket layer (SSL) certification on } \\
\text { the web server }\end{array}$ \\
\hline 4 & 1.2 .2 SQL Security & The supportability of encryption capabilities within the database \\
\hline 5 & 2.1 .1 Web-based style & The ability to create, upload, and delete templates via a web browser \\
\hline 6 & 2.1 .2 Multiple templates per site & The ability to choose a different template for each page \\
\hline 7 & 2.1 .3 Multiple menu types & The ability to choose from different menu types \\
\hline 8 & 2.1 .4 Dynamic Menus & The ability to create menus that are dynamically updated based on the site-map \\
\hline 9 & 2.1 .5 Multilingual contents & The ability to create sites with multilingual contents \\
\hline 10 & 2.2 .1 Visitor tracking & The ability to report the number of visitors per time period \\
\hline 11 & 2.2 .2 Contents tracking & The ability to report on the number of downloads per time Period \\
\hline 12 & 2.2 .3 Log-in History & The ability to keep track of who logged in, when, and what is his/her IP address. \\
\hline 13 & 3.1 Drag and Drop & The ability to position contents in a drag-and-drop fashion \\
\hline 14 & 3.2 Preview & The ability to preview contents online before publishing \\
\hline 15 & 3.3 Spell Checker & The ability to check spelling by a built-in spell checker \\
\hline 16 & 3.4 Undo (upto 10 levels) & The ability to undo performed operations \\
\hline 17 & 3.5 Image Resizing & $\begin{array}{l}\text { The ability to resize images within articles without affecting the original stored } \\
\text { image }\end{array}$ \\
\hline 18 & 3.6 File type Conversion & The ability to convert an image from one format to another \\
\hline 19 & 4.1 Static Content export & The ability of the system to export its contents as static HTML so it may be served \\
\hline
\end{tabular}




\begin{tabular}{|c|l|l|}
\hline 20 & 4.2 Page Caching & by static HTML servers \\
\hline 21 & 5.1 Manuals & $\begin{array}{l}\text { The ability to cache pages so as to save the time needed for creating it when it is } \\
\text { requested again. }\end{array}$ \\
\hline 22 & 5.2 Online Help & $\begin{array}{l}\text { The availability and quality of additional books and manuals to explain the system } \\
\text { installation process }\end{array}$ \\
\hline 23 & 5.3 Videos and Demos & The availability and quality of the online installation help \\
\hline 24 & 5.4 Mailing list & The availability and quality of videos explaining the system installation process \\
\hline 25 & 5.5 Public forum & $\begin{array}{l}\text { The availability of a mailing list service that includes latest news, updates, etc to the } \\
\text { system }\end{array}$ \\
\hline 26 & 6.1 Blog & The availability and quality of a public forum or discussion board for the system \\
\hline 27 & 6.2 Chat & The availability of a blog facility \\
\hline 28 & 6.3 Forum & The availability of an real-time online chat facility \\
\hline 29 & 6.4 Image Gallery & The availability of a message board creation and management Utility \\
\hline 30 & 6.5 Graph and chart & The ability to create a gallery-page with thumbnails of images stored in the database \\
\hline 31 & 6.6 Search Engine & The ability of the system to create graphs and charts based on some data sets \\
\hline & & $\begin{array}{l}\text { The availability of an integrated search engine for searching and indexing contents. } \\
\text { The users can then use this engine to search the contents }\end{array}$ \\
\hline
\end{tabular}

\section{PRIORITIZING SOFT GOALS USING} AHP

We then apply step 4 of our approach which involves prioritizing the soft goals. We make use of AHPs pair wise comparison technique for this purpose. In case of a multi-level hierarchy, this is done by applying AHP starting from root level goals to leaf level goals. Local weights are calculated among same level goals using AHP. Global weights are the product of all local weights proceeding from leaf to root. The result of this step is shown in table 5.

Table 5. Calculation of Local and Global weights

\begin{tabular}{|c|c|c|c|c|c|c|}
\hline Goal (L1) & $\begin{array}{c}\text { Local } \\
\text { Weight }\end{array}$ & Sub goal (L2) & $\begin{array}{c}\text { Local } \\
\text { Weight }\end{array}$ & Sub goal $(\mathbf{L 3})$ & $\begin{array}{c}\text { Local } \\
\text { Weight }\end{array}$ & $\begin{array}{l}\text { Global } \\
\text { Weight }\end{array}$ \\
\hline \multirow[t]{4}{*}{ 1.Security } & \multirow[t]{4}{*}{.023} & \multirow[t]{2}{*}{ 1.1 Application Security } & \multirow[t]{2}{*}{.167} & $\begin{array}{l}\text { 1.1.1 Human vs PC } \\
\text { Verification }\end{array}$ & 0.875 & 0.0032 \\
\hline & & & & $\begin{array}{l}\text { 1.1.2 Authentication } \\
\text { extensibility }\end{array}$ & 0.125 & 0.0004 \\
\hline & & \multirow[t]{2}{*}{ 1.2 Data Security } & \multirow[t]{2}{*}{.833} & 1.2.1 Support SSL Protocol & 0.833 & 0.0159 \\
\hline & & & & 1.2.2 SQL Security & 0.167 & 0.0031 \\
\hline \multirow[t]{8}{*}{ 2.Management } & \multirow[t]{8}{*}{.032} & \multirow[t]{5}{*}{ 2.1 Style Management } & \multirow[t]{5}{*}{0.833} & 2.1.1 Web-based style & 0.512 & 0.0136 \\
\hline & & & & $\begin{array}{l}\text { 2.1.2 Multiple templates per } \\
\text { site }\end{array}$ & 0.063 & 0.0166 \\
\hline & & & & 2.1.3 Multiple menu types & 0.261 & 0.0695 \\
\hline & & & & 2.1.4 Dynamic Menus & 0.129 & 0.0343 \\
\hline & & & & 2.1.5 Multilingual contents & 0.033 & 0.0087 \\
\hline & & \multirow[t]{3}{*}{ 2.2 Web-Statics } & \multirow[t]{3}{*}{0.167} & 2.2.1 Visitor tracking & 0.657 & 0.0034 \\
\hline & & & & 2.2.2 Contents tracking & 0.146 & 0.0007 \\
\hline & & & & 2.2.3 Log-in History & 0.196 & 0.0010 \\
\hline \multirow[t]{6}{*}{ 3. Ease of Use } & \multirow[t]{6}{*}{.519} & 3.1 Drag and Drop & .228 & & & 0.1183 \\
\hline & & 3.2 Preview & .228 & & & 0.1183 \\
\hline & & 3.3 Spell Checker & .228 & & & 0.1183 \\
\hline & & $\begin{array}{l}\text { 3.4 Undo (upto } 10 \\
\text { levels) }\end{array}$ & .228 & & & 0.1183 \\
\hline & & 3.5 Image Resizing & .044 & & & 0.0228 \\
\hline & & $\begin{array}{l}3.6 \text { File type } \\
\text { Conversion }\end{array}$ & .044 & & & 0.0228 \\
\hline \multirow[t]{2}{*}{ 4. Efficiency } & \multirow[t]{2}{*}{.115} & $\begin{array}{l}\text { 4.1 Static Content } \\
\text { export }\end{array}$ & 0.25 & & & 0.0287 \\
\hline & & 4.2 Page Caching & 0.75 & & & 0.0862 \\
\hline \multirow{5}{*}{$\begin{array}{l}\text { 5. Help and } \\
\text { Support }\end{array}$} & \multirow[t]{5}{*}{.207} & 5.1 Manuals & 0.506 & & & 0.1047 \\
\hline & & 5.2 Online Help & 0.130 & & & 0.0269 \\
\hline & & 5.3 Videos and Demos & 0.273 & & & 0.0565 \\
\hline & & 5.4 Mailing list & 0.031 & & & 0.0064 \\
\hline & & 5.5 Public forum & 0.060 & & & 0.0124 \\
\hline
\end{tabular}




\begin{tabular}{|l|l|l|l|l|l|}
\hline \multirow{3}{*}{$\begin{array}{l}\text { 6. Richness of } \\
\text { built-in tools }\end{array}$} & .101 & 6.1 Blog & 0.348 & & 0.0351 \\
\cline { 3 - 5 } & 6.2 Chat & 0.072 & & 0.0072 \\
\cline { 3 - 5 } & 6.3 Forum & 0.045 & & 0.0045 \\
\cline { 3 - 5 } & 6.4 Image Gallery & 0.142 & & 0.0143 \\
\cline { 2 - 5 } & 6.5 Graph and chart & 0.045 & & 0.0045 \\
\cline { 2 - 5 } & 6.6 Search Engine & 0.349 & & 0.0351 \\
\hline
\end{tabular}

\section{COMBINING GORE, TOPSIS AND} AHP

While AHP shows a clear direction to take, TOPSIS by its very nature provides a confirmation of the chosen alternative by adding mathematical rigour to the process of decision making. Thus we augment the existing GORE method with TOPSIS. The basic steps involved in combining GORE with TOPSIS and AHP involves the following.

i) Convert contribution link identified previously to numerical values. We make use of a step proposed in Quality function deployment (QFD) technique for this purpose. Quality function deployment (QFD) is a "method to transform user demands into design quality, to deploy the functions forming quality, and to deploy methods for achieving the design quality into subsystems and component parts, and ultimately to specific elements of the manufacturing process [17]. Many QFD techniques [18, 19 and 20] employ a 4-point or 5-point scale to convert the qualitative links to quantitative value. To our approach, we consider a 4-point scale for converting the contribution links to a numerical value. Column three of Table 2 specifies the value which we have chosen in our approach. These values are entered as shown in Table 6. For example, identifier 1 refers to Human vs PC Verification. For Drupal, e Z Publish and M D Pro the respective contribution links are --, -- and ++. Hence the numbers to be entered in Table 6 for each of the alternative are 1, 1 and 9 respectively.

ii) Apply TOPSIS technique: The three alternatives, the numeric values of contribution links and the 31 prioritized soft goals are given as input to TOPSIS technique. Due to space constraint all the 31 soft goals are not shown in Table 6 . The numbers from 1 to 31 refer to the identifier field of Table 4 . The TOPSIS procedure consists of the following steps:

(1) Calculate the normalized decision matrix. The normalized value $r_{i j}$ is calculated as

$$
r_{i j}=f_{i j} / \sqrt{ } \int_{j=1} f_{i j}^{2}
$$

$\mathrm{j}=1,2, \ldots . . \mathrm{J} ; \mathrm{i}=1,2, \ldots . . \mathrm{n}$;

$f_{i j}$ refers to the values entered for each alternative against each of the criteria. This formula involves squaring of all numbers, finding the sum of each column and then finding the square root of this sum $\left(\mathrm{r}_{\mathrm{ij}}\right) . \mathrm{r}_{\mathrm{ij}}$ is shown in table 6 . Then divide the contribution link values of each column by $r_{i j}$.
(2) Calculate the weighted normalized decision matrix. The weighted normalized value $v_{i j}$ is calculated as:

$$
\begin{gathered}
v_{i j}=w_{i} r_{i j}, \\
j=1, \ldots \ldots . J ; i=1, \ldots \ldots, n ;
\end{gathered}
$$

where $\mathrm{w}_{\mathrm{i}}$ is the weight of the $\mathrm{i}^{\text {th }}$ attribute or criterion, and

$$
\int_{\mathrm{i}=1}^{\mathrm{n}} \mathrm{W}_{\mathrm{i}}=1
$$

This formula involves multiplying the priorities of soft goals with the corresponding column value.

(3) Determine the ideal and negative-ideal solution as per the following formula:

$$
\begin{aligned}
& \mathrm{A}^{*}=\left\{\mathrm{v}_{1}^{*}, \ldots, \mathrm{v}_{\mathrm{n}}^{*}\right\} \\
& =\left\{\left(\max _{j} v_{i j} \mid i \in I^{1}\right),\left(\min _{j} v_{i j} \mid i \in I^{1 I}\right)\right\} \\
& \mathrm{A}^{-}=\left\{\mathrm{v}_{1}^{-}, \ldots, \mathrm{v}_{\mathrm{n}}^{-}\right\} \\
& =\left\{\left(\min _{j} v_{i j} \mid i \in I^{1}\right),\left(\max _{j} v_{i j} \mid i \in I^{1 I}\right)\right\}
\end{aligned}
$$

where $\mathrm{I}^{1}$ is associated with benefit criteria, and $\mathrm{I}^{11}$ is associated with cost criteria. In our example only benefit criteria is considered.

Ideal solution $\left(\mathrm{A}^{*}\right)$ refers to highest value in each column and negative-ideal solution $\left(\mathrm{A}^{-}\right)$refers to least value in each column. $\mathrm{A}^{*}$ and $\mathrm{A}^{-}$value are shown in the graphs 7 and 8 respectively.

(4) Calculate the separation measures, using the ndimensional Euclidean distance. The separation of each alternative from the ideal solution is given as:

$$
D_{j}^{*}=\sqrt{\prod_{i=1}^{n} v_{i j}-v_{i}^{*} r^{2}}
$$

Similarly, the separation from the negative ideal solution is given as:

$$
D_{j}^{-}=\sqrt{\prod_{i=1}^{n} v_{i j}-v_{i}^{-} r^{2}}
$$

(5) Calculate the relative closeness to the ideal solution. The relative closeness of the alternative $a_{j}$ with respect to $A^{*}$ is defined as:

$$
C_{j}^{*}=D_{j}^{-} / D_{j}^{*}+D_{j}^{-} r
$$

(6) Rank the preference order. 
Table 6. Calculation of $r_{i j}$ (Step 1 of section 5)

\begin{tabular}{|c|c|c|c|c|c|c|c|c|c|c|c|c|c|c|c|c|}
\hline $\begin{array}{c}\text { Soft } \\
\text { Goals / } \\
\text { Alternati } \\
\text { ve }\end{array}$ & 1 & 2 & 3 & 4 & 5 & 6 & 7 & 8 & 9 & 10 & \multirow{5}{*}{$\begin{array}{l}11 \text { to } 26 \\
\text { identifiers } \\
\text { of soft } \\
\text { goals and } \\
\text { their } \\
\text { values }\end{array}$} & 27 & 28 & 29 & 30 & 31 \\
\hline $\begin{array}{c}\text { Soft goal } \\
\text { priority } \\
w_{i}\end{array}$ & .032 & $\begin{array}{c}.0 \\
04\end{array}$ & $\begin{array}{c}.0 \\
15 \\
9\end{array}$ & $\begin{array}{c}.003 \\
1\end{array}$ & $\begin{array}{c}.013 \\
6\end{array}$ & .0166 & .0695 & .0343 & .0007 & .0034 & & $\begin{array}{c}.007 \\
2\end{array}$ & $\begin{array}{c}.0 \\
04 \\
5\end{array}$ & $\begin{array}{l}.0 \\
14 \\
3 \\
\end{array}$ & $\begin{array}{c}.0 \\
\mathbf{0 4} \\
5 \\
\end{array}$ & $\begin{array}{c}.0 \\
35 \\
1\end{array}$ \\
\hline Drupal & 1 & 9 & 7 & 9 & 9 & 9 & 7 & 1 & 9 & 9 & & 1 & 9 & 1 & 1 & 9 \\
\hline $\begin{array}{c}\text { e Z } \\
\text { Publish } \\
\end{array}$ & 1 & 9 & 9 & 9 & 9 & 9 & 7 & 1 & 9 & 1 & & 1 & 9 & 9 & 1 & 9 \\
\hline MD Pro & 9 & 9 & 1 & 9 & 9 & 9 & 7 & 1 & 9 & 9 & & 1 & 1 & 1 & 1 & 9 \\
\hline$r_{i j}$ & 9.11 & $\begin{array}{l}15 \\
.8\end{array}$ & $\begin{array}{l}11 \\
.4\end{array}$ & $\begin{array}{c}15.5 \\
8\end{array}$ & $\begin{array}{c}15.5 \\
8\end{array}$ & 15.58 & 12.12 & 1.73 & 15.58 & 12.76 & & 1.73 & $\begin{array}{l}12 \\
.7\end{array}$ & $\begin{array}{c}9 . \\
11\end{array}$ & $\begin{array}{l}1 . \\
73\end{array}$ & $\begin{array}{l}15 \\
.5 \\
8\end{array}$ \\
\hline
\end{tabular}

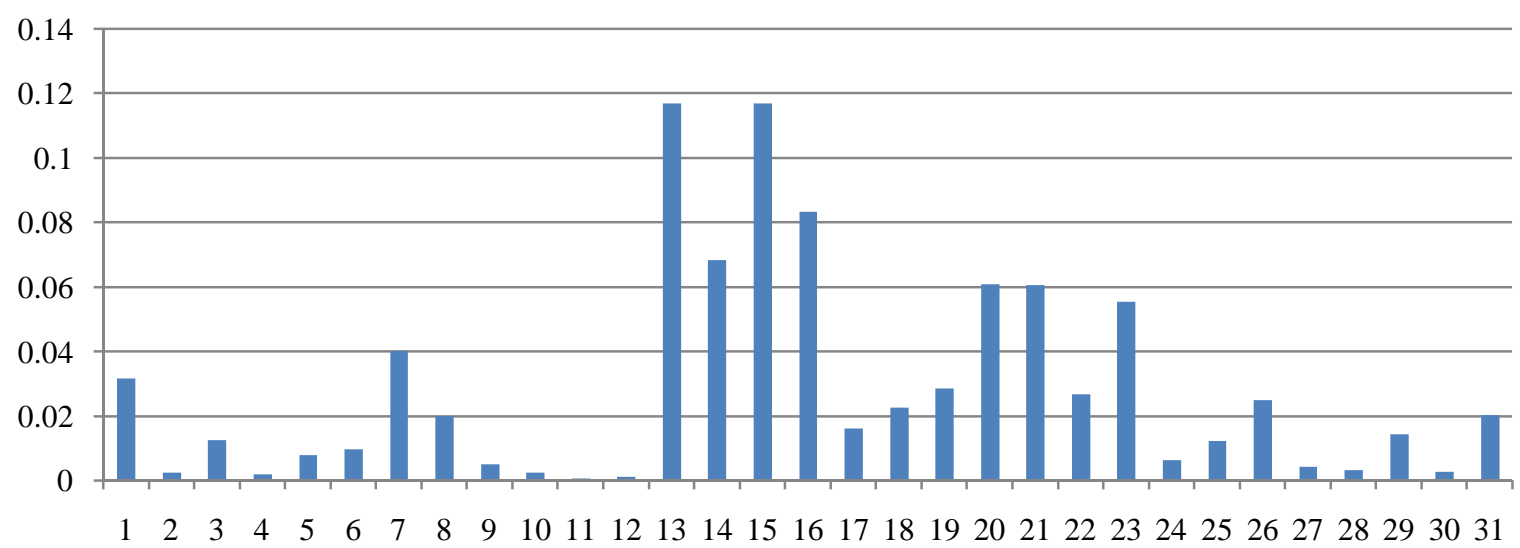

Graph 7: Values of $A^{*}$ (Highest values in each column after step 3 in section 5)

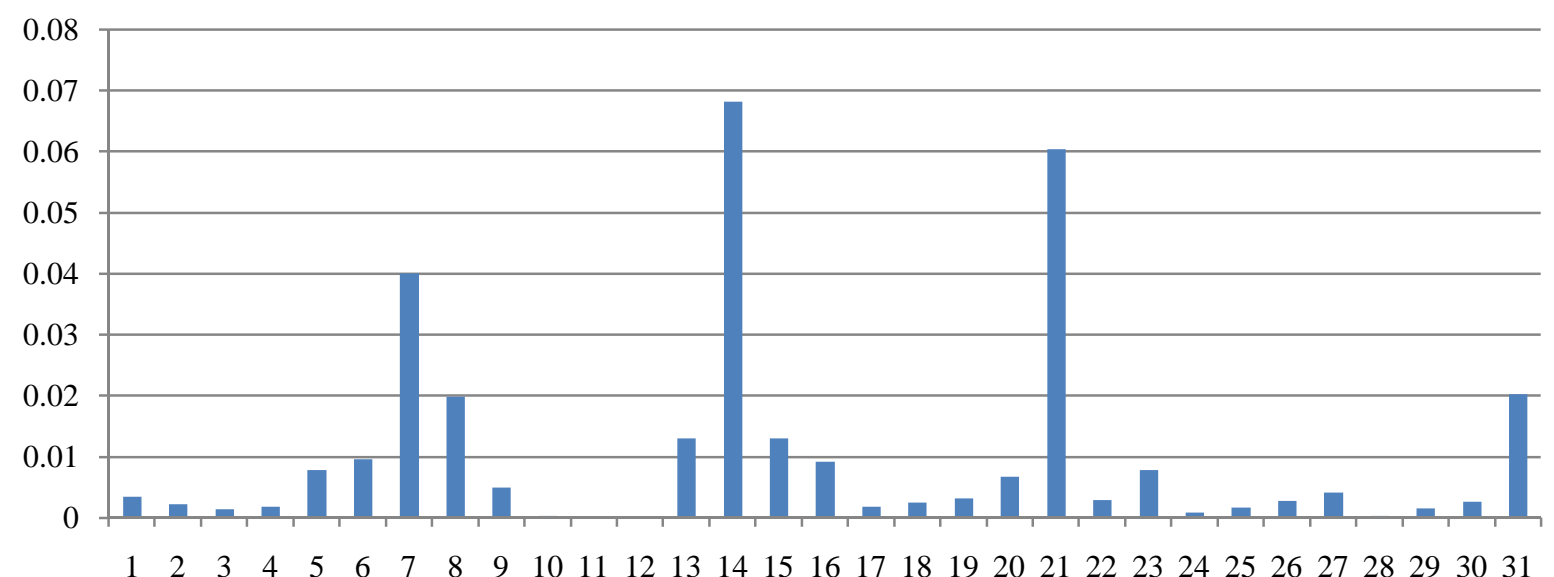

Graph 8: Values of $A^{-}$(Lowest values in each column after step 3 of section 5)

Table 9 shows the separation measures $\mathrm{Dj} *$ and $\mathrm{Dj}$ - from ideal solution and ideal negative solution respectively. Relative closeness to the ideal solution $\mathrm{Cj}^{*}$ is calculated using the formula 6 and is shown in Table 9. The values shown in Table
9 and graph 10 clearly indicate that Drupal is the best alternative followed by E Z Publish and M D Pro which fulfills the set of soft goals identified for the problem. 
Table 9. Relative values of each alternative, Relative Closeness to the ideal and ranking of alternatives

\begin{tabular}{|c|c|c|c|c|}
\hline & $\mathbf{D j}^{*}$ & $\mathbf{D j}^{*}$ & $\mathbf{C}_{\mathbf{j}}{ }^{*}$ & $\begin{array}{c}\text { Ranking of } \\
\text { alternatives }\end{array}$ \\
\hline Drupal & 0.03987 & 0.1847 & 0.8224 & 1 \\
\hline e Z Publish & 0.1603 & 0.1001 & 0.3843 & 2 \\
\hline M D Pro & 0.1869 & 0.0281 & 0.1309 & 3 \\
\hline
\end{tabular}

1

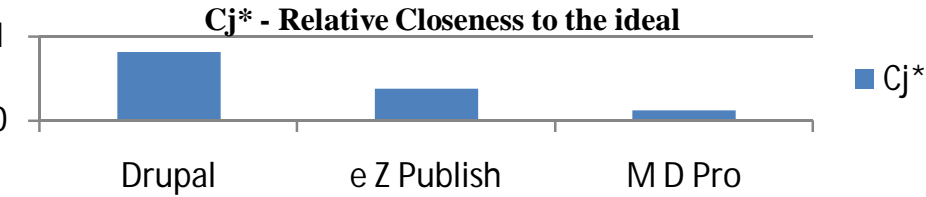

Graph 10. Output of TOPSIS process $\left(\mathrm{Cj}^{*}\right.$ Relative closeness to the ideal)

\section{DISCUSSION}

In our earlier work in [25], we had combined GORE with AHP by considering the case study of choosing a CMS. We supplement the method with TOPSIS which adds more mathematical rigour to our approach. The steps proposed have been validated with case studies. Here are the following observations about the results obtained. The success of this approach depends on the following factors:

i) Clear identification of hard goals and soft goals.

ii) The identification of qualitative and quantitative criteria is an important step in the process since they directly contribute to identification of contribution links. These contribution links play a major role in choosing the best alternative.

iii) Appropriate stakeholders' needs to be identified in prioritizing soft goals.

AHP is a technique for computing priorities which is widely used in many domains. The data entered by a stakeholder is checked for consistency by measuring Consistency Index or Ratio (CI / CR). If CI > 0.1, then it implies that the priorities given by a stakeholder are not consistent. In the existing GORE literature, there exists technique which makes use of formal techniques $[3,14]$ in choosing the best alternative. They make use of temporal logic and label propagation algorithms. Our approach differs in adopting a quantitative way of evaluating the alternative using AHP

One of the existing methods which make use of a quantitative approach for decision support system in GORE is Attributed Goal Oriented Requirements Analysis (AGORA) [24]. One of the future works suggested by the authors mention use of AHP to assign the values subjectively. We have used AHP and TOPSIS which are widely used for decision support system in software development. The steps involved in TOPSIS are accomplished with a program implemented using Java.

\subsection{Validation of the Proposed Method}

The approach to validate the proposed method of combining AHP, TOPSIS and GORE is done by considering the opinion of the experts. Problem description of all systems has been given to 6 subject experts who have to recommend the CMS to be chosen among the three. Experts chosen are from industry with a minimum experience of 5 years. The participants are required to provide rationale for the decisions which they arrive at. The experts will use their experience in deciding the alternative and are not aware about our proposed method. The comparison of the decision taken by experts with the results obtained by our approach is shown in Table 11 .
Results shown in Table 10 clearly conveys that Drupal is chosen as the best alternative by five experts as well as our approach. Four experts have the same ranking of alternatives as our method. The experts have arrived at a decision based on their experience, importance of soft goals and in consultation with other senior colleagues. We can clearly infer that our method results are in tune with the experts. The advantage of our method is that it provides a metric and rationale for the decision arrived at using AHP and TOPSIS unlike experts who rely more on experience and intuition.

Table 11. Comparison of our method with experts

\begin{tabular}{|c|c|c|}
\hline Subject & Ranking of alternatives & $\begin{array}{l}\text { Chosen } \\
\text { alternative }\end{array}$ \\
\hline $\begin{array}{l}\text { Our } \\
\text { method }\end{array}$ & $\begin{array}{l}\text { Drupal, e Z Publish, M } \\
\text { Pro }\end{array}$ & Drupal \\
\hline Expert 1 & $\begin{array}{l}\text { Drupal, e Z Publish, M } \\
\text { Pro }\end{array}$ & Drupal \\
\hline Expert 2 & $\begin{array}{lllll}\begin{array}{l}\text { Drupal, } \\
\text { Publish }\end{array} & \text { M } & \text { Pro, } & \text { e } & \text { Z } \\
\end{array}$ & Drupal \\
\hline Expert 3 & $\begin{array}{l}\text { Drupal, e Z Publish, M } \\
\text { Pro }\end{array}$ & Drupal \\
\hline Expert 4 & e Z Publish, Drupal, M Pro & e Z Publish \\
\hline Expert 5 & $\begin{array}{lllll}\text { Drupal, } & \text { M } & \text { Pro, } & \text { e } & \text { Z } \\
\text { Publish } & & & & \end{array}$ & Drupal \\
\hline Expert 6 & $\begin{array}{l}\text { Drupal, e Z Publish, M } \\
\text { Pro }\end{array}$ & Drupal \\
\hline
\end{tabular}

\section{FUTURE WORK}

The future work will be carried out in the following areas:

- We have assumed the contribution links as either contributing positively or negatively. There are situations when the soft goals conflict with one another. For example, enhancing security can compromise on the performance of the system. This aspect will be considered in our future work.

- While converting the contribution links to a numerical value, we have adopted a linear scale. We will be studying the effect of using a nonlinear scale of values on the final outcome.

- Comparison of our approach with other techniques by identifying suitable metrics.

- Technique can be used in negotiating SLA (Service Level Agreement) for Cloud Computing where service quality plays a vital role.

- A software tool to support our method. 


\section{CONCLUSION}

In this paper, we have made an attempt to integrate GORE method with AHP and TOPSIS in arriving at a decision. The method gives consistent results which depend on the quality of the goals identified and their priority. The same process might yield a different outcome if we are going to select a CMS for an e-commerce site. Security becomes more important and the global weights for the soft goals will change as a result. We have identified further work which will be carried out in the future.

\section{REFERENCES}

[1] Joerg Doerr, Daniel Kerkow, Tom Koenig, Thomas Olsson, Takeshi Suzuki, "Non-Functional Requirements in Industry - Three Case Studies Adopting an Experience-based NFR Method", in Proceedings of the 2005 13th IEEE International Conference on Requirements Engineering, 1995

[2] Mylopoulos, J., Chung, L., Nixon B. “ Representing and Using Nonfunctional Requirements: A Process-Oriented Approach", IEEE Transactions on Software Engineering, 18(6), pp 483-497, 1992

[3] Van Lamsweerde A, "Goal-Oriented Requirements Engineering: A Guided Tour" in Proceedings of the 5th IEEE International Symposium on Requirements Engineering, August 2001, IEEE Computer Society, Washington

[4] Gunther Ruhe, "Software Engineering Decision Support and Empirical Investigations - A Proposed Marriage," in Workshop on Empirical Studies in Software Engineering (WSESE), 2003

[5] Hannes Omasreiter, "Balanced Decision Making in Software Engineering - General Thoughts and a Concrete Example from Industry," in First International Workshop on the Economics of Software and Computation (ESC), 2007

[6] Steve Easterbrook, Janice Singer, Margaret-Anne Storey, Daniela Damian, "Selecting Empirical Methods for Software Engineering Research," in Guide to Advanced Empirical Software Engineering, Section III, 285-311, 2008

[7] Jo E. Hannay, Dag I.K. Sjøberg, Tore Dyba, "A Systematic Review of Theory Use in Software Engineering Experiments," IEEE transactions on Software Engineering, VOL. 33, NO. 2, Feb 2007

[8] Jenny Price, Jacob Cybulski, "The Importance of IS Stakeholder Perspectives and Perceptions to Requirements Negotiation," in AWR, Adelaide, Australia, 2006

[9] Ana Ivanović and Pierre America, "Information Needed for Architecture Decision Making," in Proceedings of the ICSE Workshop on Product Line Approaches in Software Engineering, 2010

[10] Vidya Lakshminarayanan, WenQian Liu, Charles L Chen, Steve Easterbrook, Dewayne E Perry, "Software Architects in Practice: Handling Requirements," in Proceedings of the conference of the Center for Advanced Studies on Collaborative research (CASCON), 2006

[11] Mohammad Shabbir Hasan, Abdullah Al Mahmood, Md. Jahangir Alam, Sk. Md. Nahid Hasan, Farin Rahman, "An Evaluation of Software Requirement Prioritization Techniques," International Journal of Computer Science and Information Security (IJCSIS), Vol. 8, No. 9, December 2010

[12] Thomas L. Saaty, "Decision making with the analytic hierarchy process," Int. J. Services Sciences, Vol. 1, No. 1,2008

[13] Haag, S.E., and Hogan P, "Research issues in software quality function deployment: A new beginning for software engineering methodologies," in Proceedings of Decision Sciences Institute ' 92 Nov. 23-25, San Francisco, California, DSI, Atlanta, Ga., pp. 926-928, 1992.

[14] J. Castro, M. Kolp, J. Mylopoulos. Towards Requirements-Driven Information Systems Engineering: The Tropos Project. Information Systems, 27(6), September 2002.

[15] H Kaiya et al, "Identifying Stakeholders and Their Preferences about NFR by Comparing Use Case Diagrams of Several Existing Systems", 12th IEEE International Requirements Engineering Conference (RE'04)

[16] Vinay S, Shridhar Aithal and Sudhakar Adiga, A GoalOriented Requirements Engineering Method for Analysing Conflicts, ICCANA, Nitte, Jan 2011

[17] Akao, Yoji. "Development History of Quality Function Deployment". The Customer Driven Approach to Quality Planning and Deployment. Minato, Tokyo 107 Japan: Asian Productivity Organization. pp. 339.

[18] G Herzwurm et al, "QFD for customer focused Requirements Engineering," in 11th IEEE International Requirements Engineering Conference, 2003

[19] Andreas Hierholzer, Georg Herzwurm, Harald Schlang, "Applying QFD for Software Process Improvement at SAP AG, Walldorf, Germany," in Proceedings of the third workshop on Software quality, ACM, 2003

[20] De Felice, A. Petrillo, "A multiple choice decision analysis: an integrated QFD - AHP Model for the Assessment of Customer Needs," International Journal of Engineering, Science and Technology, Vol. 2, No. 9, pp. 25-38, 2010

[21] Chen, S.J., Hwang, C.L., 1992. Fuzzy Multiple Attribute Decision Making: Methods and Applications. SpringerVerlag, Berlin.

[22] Hwang, C.L., Yoon, K., 1981. Multiple Attribute Decision Making. In: Lecture Notes in Economics and Mathematical Systems 186. Springer-Verlag, Berlin.

[23] Abdallah Sami Abbas Shehata Mohamed, Ph.D thesis on Decision Support for Selecting COTS Software Products Based on Comprehensive Mismatch Handling.

[24] Kaiya. H, Nagano Horai H, Saeki M, AGORA: attributed goal-oriented requirements analysis method, International Conference on Requirements Engineering, 2002 Proceedings

[25] Vinay S, Shridhar Aithal, Sudhakara Adiga, A Quantitative Approach Using Goal-Oriented Requirements Engineering Methodology and Analytic Hierarchy Process in Selecting the Best Alternative, Advances in Intelligent Systems and Computing Volume 174, 2012, pp 441-454. 